\title{
Social Capital accumulation and the role of the researcher: An example of a transdisciplinary visioning process for the future of agriculture in
}

\section{Europe.}

Mckee, A., Guimarães, M.H., Pinto-Correia, T., 2015, Social Capital accumulation and the role of the researcher: An example of a transdisciplinary visioning process for the future of agriculture in Europe. Environmental Science \&Policy, 88-99

http://dx.doi.org/10.1016/j.envsci.2015.02.006

Abstract:

Transdisciplinarity is a demanding paradigm, considered by many in the literature as the way to move forward in terms of science and policy integration. In this paper we present the example of a tailored transdisciplinary (TD) Process to tackle a key topic of European Policy The future of agriculture at the regional level. This Phased process was followed in seven regions across Europe and involved the co-construction of future visions, engaging both researchers and a range of relevant stakeholders. This Paper presents results based on a critical reflection made by researchers and stakeholders in Portugal and Scotland, through- out the participatory process. These results provide insights into the roles and responsibilities of researchers and stakeholders in TD processes. One main conclusion is that accumulated social capital can be essential to initiate and maintain a TD process, and requires a commitment between the research community and the surrounding society. Our analysis demonstrates the challenges of implementing a TD process within the temporal frame/boundaries of a research project and the added value of having transdisciplinarity as part of the long term strategy of a research group, not just one part of a specific project. Not acknowledging this may lead to disappointment and fatigue amongst those connecting with researchers. We also found that researchers position themselves differently in a TD Process depending on their soft skills, experience and knowledge about transdisciplinarity; hence we call attention to the need to work more explicitly with these skills in the research environment and to present this concept in an early stage of researcher training, if better transdisciplinarity is to be achieved. 